\title{
Cryptococcal meningitis complicating systemic lupus erythematosus: two patients treated with flucytosine and amphotericin B
}

\author{
D. C. E. SPELler, F. FAKUNLE, S. A. CAIRNS, AND MARY STEPHENS \\ From Bristol Royal Infirmary, Bristol BS2 $8 \mathrm{HW}$
}

SUMMARY Two fatal cases of cryptococcal meningitis complicating adrenocorticosteroid-treated $\omega_{\tilde{\omega}}^{\omega}$ systemic lupus erythematosus are reported. In one patient who was treated with flucytosine alone,, $\mathrm{A}$ after an initial period of improvement cryptococci resistant to flucytosine were isolated, and sub-은 sequent amphotericin B treatment did not alter the progress of the disease. In the second patient, $\rightarrow$ who received both drugs concurrently, resistant cryptococci did not appear and the patient recovered sufficiently to return home. Flucytosine-resistant mutants could be demonstrated in vitro in thes original cryptococcal isolates from both patients. The use of flucytosine and amphotericin B in $\overrightarrow{0}$ combination is discussed.

Disseminated cryptococcal infection is a rare disease in Britain and almost invariably associated with severe impairment of host defences, particularly the immunosuppression of transplant surgery. Khan and Sbar (1975) noted the association of cryptococcal meningitis with systemic lupus erythematosus, especially after treatment with adrenocorticosteroids, and pointed out that diagnosis of this complication is rarely made during life, although successful treatment is possible.

Amphotericin B and, more recently, flucytosine (5-fluorocytosine) have been successful in the treatment of cryptococcal meningitis, though neither agent is ideal. The greatest discrimination must be shown in the administration of these chemotherapeutic agents if the infection is to be eradicated from the patient, whose own defences can barely assist this process, and the patient is to be unharmed by the treatment. We here present two patients seen within a year at this hospital, both of whom died, but in whom the clinical course and laboratory observations give indications for successful treatment of the condition.

\section{Laboratory methods}

Cryptococcus neoformans was isolated on Sabouraud's dextrose-peptone agar and identified in

Received for publication 12 July 1976 secretions and in culture by morphology in India inkö preparations. Its identity was confirmed by mor $\stackrel{0}{\circ}$ phology in cornmeal agar, and assimilation and $\mathbb{B}$ fermentation tests (after Lodder, 1970), by pig $\overrightarrow{\overrightarrow{0}}$ mentation on a medium containing an extract of 3 Guizotia abyssinica-'Niger seed' (Staib, 1962), and? by pathogenicity on intracerebral injection in suck ling mice. Blood was cultured by adding $5 \mathrm{ml}$ to nutrient broth with $0.05 \%$ sodium polyanethop sulphonate, and a pour plate also was prepared by adding $1 \mathrm{ml}$ of blood to $19 \mathrm{ml}$ of molten Sabouraud's agar.

All experiments on the antifungal activity of flucytosine were performed using yeast nitrogen base? (Difco) with dextrose and asparagine (Shadomy et al., 1969), or yeast morphology agar (Difco). In experiments with more than 40 hours' incubation flucytosine was assayed in the culture medium at the end of the experiment to ensure that no significanto decline in antifungal activity had occurred. Viablew counts were estimated by the method of Miles and Misra (1938). Minimum inhibitory concentrationso (MIC) for flucytosine and amphotericin were estimated by the methods of Shadomy et al. (1969)? Serum and CSF concentrations of flucytosine were estimated by a plate diffusion method, using surface inoculation with a sensitive Candida albicans isolate $\stackrel{?}{?}$ Amphotericin B does not affect flucytosine assay in this sytem (Kaspar and Drutz, 1975). Amphotericin in the presence of flucytosine was assayed by 
similar method, with the addition of $0.01 \%$ cytosine to the medium to inactivate flucytosine (Holt, 1975).

Evidence of synergy between flucytosine and amphotericin B was sought using the methods of Medoff et al. (1971). Mutational resistance was demonstrated by the replica plating technique of Lederberg and Lederberg (1952).

\section{Case reports}

\section{CASE 1}

Mrs P. McK., a 48-year-old Jamaican resident in the UK for 10 years, presented with a short febrile illness associated with oedema, ascites, hypertension, and proteinuria. LE cell preparations were positive and a renal biopsy showed acute glomerulonephritis consistent with systemic lupus erythematosus. She improved with prednisone $(80 \mathrm{mg}$ daily, reducing to $20 \mathrm{mg}$ daily) and diuretics. Azathioprine was later added. She remained hypoproteinaemic with proteinuria and an elevated blood urea $(11.7 \mathrm{mmol} / \mathrm{l})$ and subsequently developed a steroid-induced diabetes mellitus, controlled by diet and chlorpropamide.

A year later, during an episode of malaise and

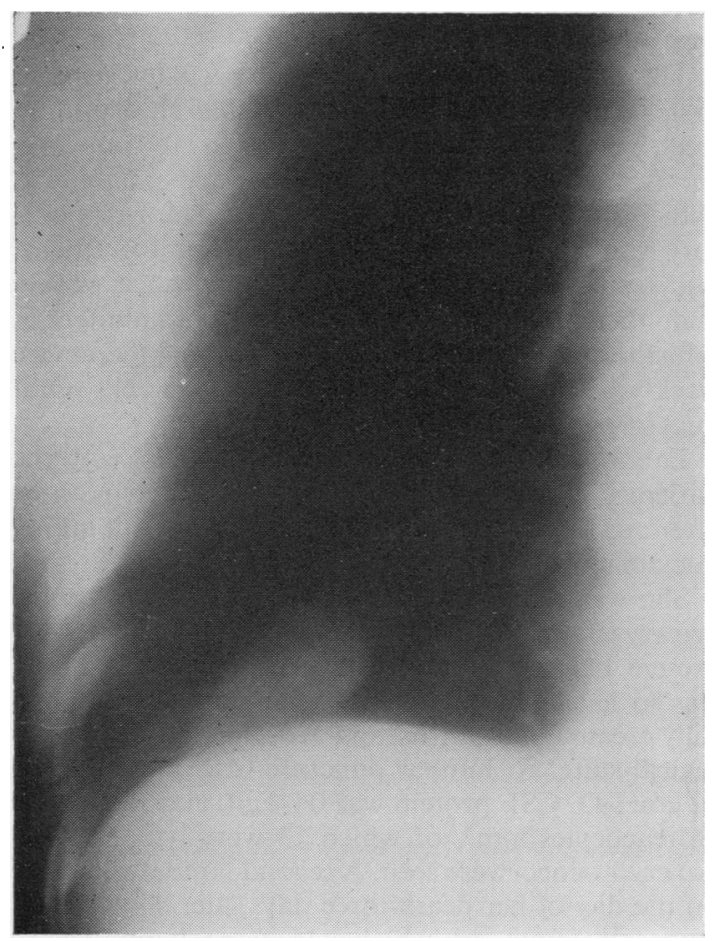

Fig. 1 Case 1. Radiograph of right lung showing cryptococcal lesion. dyspnoea, a mass was seen on chest $x$-ray in the lower lobe of the right lung (Fig. 1). Believed at the time to be neoplastic, this was presumably the primary cryptococcal lesion. It was still present, essentially unchanged, at the time of her last admission.

Two years after the onset of her illness she was admitted complaining of headache and drowsiness. She was pyrexial $\left(40^{\circ} \mathrm{C}\right)$ but had no meningism or focal neurological signs. A clinical diagnosis of septicaemia was made and she was treated with broad-spectrum antibiotics. Because of the lack of clinical response a lumbar puncture was performed. The cerebrospinal fluid showed a pleocytosis and $C$. neoformans was isolated. Results of this and subsequent CSF examinations are summarised in Table 1. Cryptococcal antigen was initially present in the CSF to a titre of $1 / 400$ but could not be detected in the serum.

In view of her renal lesion it was not thought desirable to treat her with amphotericin $B$, and so flucytosine was administered in a dose of $150 \mathrm{mg} / \mathrm{kg}$ per day ( $2 \mathrm{~g}$ six-hourly). This was well tolerated and satisfactory serum and CSF concentrations were obtained (Table 2), but there was little clinical improvement. At first there was a reduction in the number of organisms visible in, and cultured from, the CSF, but after 28 days of flucytosine treatment the numbers increased again, and cryptococci highly resistant to flucytosine were isolated.

Daily intravenous amphotericin $B$ was then started, in increasing doses up to $1 \mathrm{mg} / \mathrm{kg}$, and just before her death the intrathecal route was also used. Flucytosine was continued until it became clear that no synergistic activity between flucytosine and amphotericin B could be demonstrated in vitro.

There was gradual deterioration in the patient's condition with no change in the CSF findings and she died 56 days after the diagnosis of cryptococcal infection had been made, and 19 days after the start of amphotericin B treatment. Permission for necropsy was refused.

She received a total dose of $390 \mathrm{~g}$ of flucytosine orally and approximately $1.3 \mathrm{~g}$ of amphotericin intravenously. No toxic effects of flucytosine were observed but the introduction of amphotericin B was followed by hypokalaemia (plasma potassium 1.9 $\mathrm{mmol} / \mathrm{l}$ ) and the plasma urea rose terminally.

\section{CASE 2}

Mrs D. D. presented at age 52 with a polyarthritis affecting mainly her wrists. Her erythrocyte sedimentation rate was $44 \mathrm{~mm}$ in one hour. Her rheumatoid factor and antinuclear factor remained persistently positive but no LE cells were ever seen. She subsequently developed Sjögren's syndrome, 
Table 1 Case 1. Cerebrospinal fluid findings

\begin{tabular}{|c|c|c|c|c|}
\hline \multicolumn{2}{|c|}{ Day of treatment } & \multicolumn{2}{|c|}{ Treatment in progress } & $\frac{\text { CSF findings }}{\text { Leucocyte count/mn }}$ \\
\hline \multirow{7}{*}{\multicolumn{2}{|c|}{$\begin{array}{r}1 \\
4 \\
7 \\
12 \\
19 \\
26 \\
35\end{array}$}} & \multicolumn{2}{|c|}{ nil } & 310 \\
\hline & & \multirow{2}{*}{\multicolumn{2}{|c|}{$\begin{array}{l}\text { flucytosine } \\
\text { flucytosine }\end{array}$}} & \multirow{2}{*}{110} \\
\hline & & & & \\
\hline & & \multicolumn{2}{|c|}{ flucytosine } & 23 \\
\hline & & & 18 \\
\hline & & & & \multirow[t]{2}{*}{1} \\
\hline & & \multirow{2}{*}{\multicolumn{2}{|c|}{$\begin{array}{l}\text { flucytosine } \\
+ \text { amphotericin }\end{array}$}} & \\
\hline \multirow{2}{*}{\multicolumn{2}{|c|}{$\begin{array}{l}42 \\
54\end{array}$}} & & & \multirow{2}{*}{$\begin{array}{r}3 \\
52 \\
4\end{array}$} \\
\hline & & am & & \\
\hline \multicolumn{5}{|c|}{ MIC $=$ minimum inhibitory concentration. } \\
\hline \multicolumn{5}{|c|}{$\begin{array}{l}\text { Table } 2 \text { Case 1. Serum and CSF concentrations of } \\
\text { flucytosine }\end{array}$} \\
\hline \multirow{3}{*}{$\begin{array}{l}\text { Day of } \\
\text { treatment }\end{array}$} & \multicolumn{4}{|c|}{ Flucytosine concentrations $(\mathrm{mg} / \mathrm{l})$} \\
\hline & \multicolumn{3}{|c|}{$\begin{array}{l}\text { Serum } \\
\text { (hours after dose) }\end{array}$} & \multirow[t]{2}{*}{$\begin{array}{l}\text { CSF } \\
2 \text { hafter dose }\end{array}$} \\
\hline & 2 & 4 & 6 & \\
\hline 12 & 100 & \multirow{3}{*}{45} & 30 & 45 \\
\hline 19 & 80 & & & 30 \\
\hline 26 & 90 & & 65 & 38 \\
\hline
\end{tabular}

pericarditis, pleural effusions, and a mononeuritis multiplex. A diagnosis of systemic lupus erythematosus was made and she was treated with corticosteroids.

Six years after her first presentation she had an episode of headache and vomiting associated with papilloedema, retinal haemorrhages and exudates, and a blood pressure of $190 / 120 \mathrm{mmHg}$. She was known to have had an IgM monoclonal gammapathy since early in her illness and on this occasion her serum IgM level was $27 \mathrm{~g} / \mathrm{l}$. Plasma viscosity was 1.92 cP (ESR $52 \mathrm{~mm}$ in $1 \mathrm{~h}$ ), and her blood urea was 9.8 $\mathrm{mmol} / \mathrm{l}$. Albuminuria was present. Her symptoms improved with plasmapheresis and chlorambucil for her macroglobulinaemia and hyperviscosity syndrome and control of her hypertension. The papilloedema resolved. She remained on large doses of corticosteroids.

One year later she returned with a short history of further headache, vomiting, and lassitude. Plasma protein electrophoresis showed that the macroglobulinaemia had not recurred. Her condition deteriorated over a three-week period and she became stuporose with meningism, bilateral papilloedema, and upgoing plantars. At lumbar puncture CSF pressure was greater than $40 \mathrm{cmH}_{2} \mathrm{O}$, the CSF protein was $0.49 \mathrm{~g} / 1$, and there were no cells in the CSF except 2500 cryptococci $/ \mathrm{mm}^{3}$. C. neoformans

was isolated from both CSF and blood (approxi mately 50 colonies per $\mathrm{ml}$ of blood).

Flucytosine was given orally twice daily because of $\vec{f}$ impaired renal function (blood urea $7.9 \mathrm{mmol} / \mathrm{l}$ creatinine clearance $20 \mathrm{ml} / \mathrm{min} / \mathrm{m}^{2}$ ). On the basis of serum assays the dose was reduced from $3 \mathrm{~g}$ twicedaily to $2 \mathrm{~g}$ twice daily; $100 \mathrm{mg}$ flucytosine were administered intrathecally twice weekly. After our experience with case 1 we added amphotericin B too the regimen beginning with $0.25 \mathrm{mg} / \mathrm{kg}$ by intravenous infusion daily and gradually increasingo to $1 \mathrm{mg} / \mathrm{kg}$ daily.

The patient's progress was unexpectedly good at? first. Within two days she was alert and cheerful and free from headache. She continued to improve, 3 surviving an episode of pneumococcal pneumonia with bacteraemia which was treated, before labora-0. tory results were known, with ampicillin. Intrathecaf flucytosine injections were reduced to once weekly? and then stopped. After 20 days amphotericin infusions were given on alternate days and then twices weekly before being stopped after eight weeks. Oraß flucytosine was continued.

Laboratory findings improved in parallel with the patient's clinical progress (Fig. 2). Three months after admission she was discharged home still taking flucytosine.

She was readmitted 10 days later having become drowsy and uncooperative. Signs of meningism were present but the papilloedema had not recurred. She ${ }^{\omega}$ was in left ventricular failure and this was success $\frac{}{2}$ fully treated without halting a decline in her neurological state. At lumbar puncture CSF pressure was $12 \mathrm{cmH}_{2} \mathrm{O}, \mathrm{CSF}$ protein was $0.84 \mathrm{~g} / 1$, and there were 16 leucocytes $/ \mathrm{mm}^{3}$, of which 13 were lymphocytes. No cryptococci were seen. A second lumbar puncture on the day of her death three days later showed $127 \stackrel{\mathrm{P}}{\mathrm{D}}$ leucocytes $/ \mathrm{mm}^{3}$, of which 116 were lymphocytes.ำ Permission for a necropsy was refused.

She had received $1260 \mathrm{~g}$ of flucytosine by mouth, 


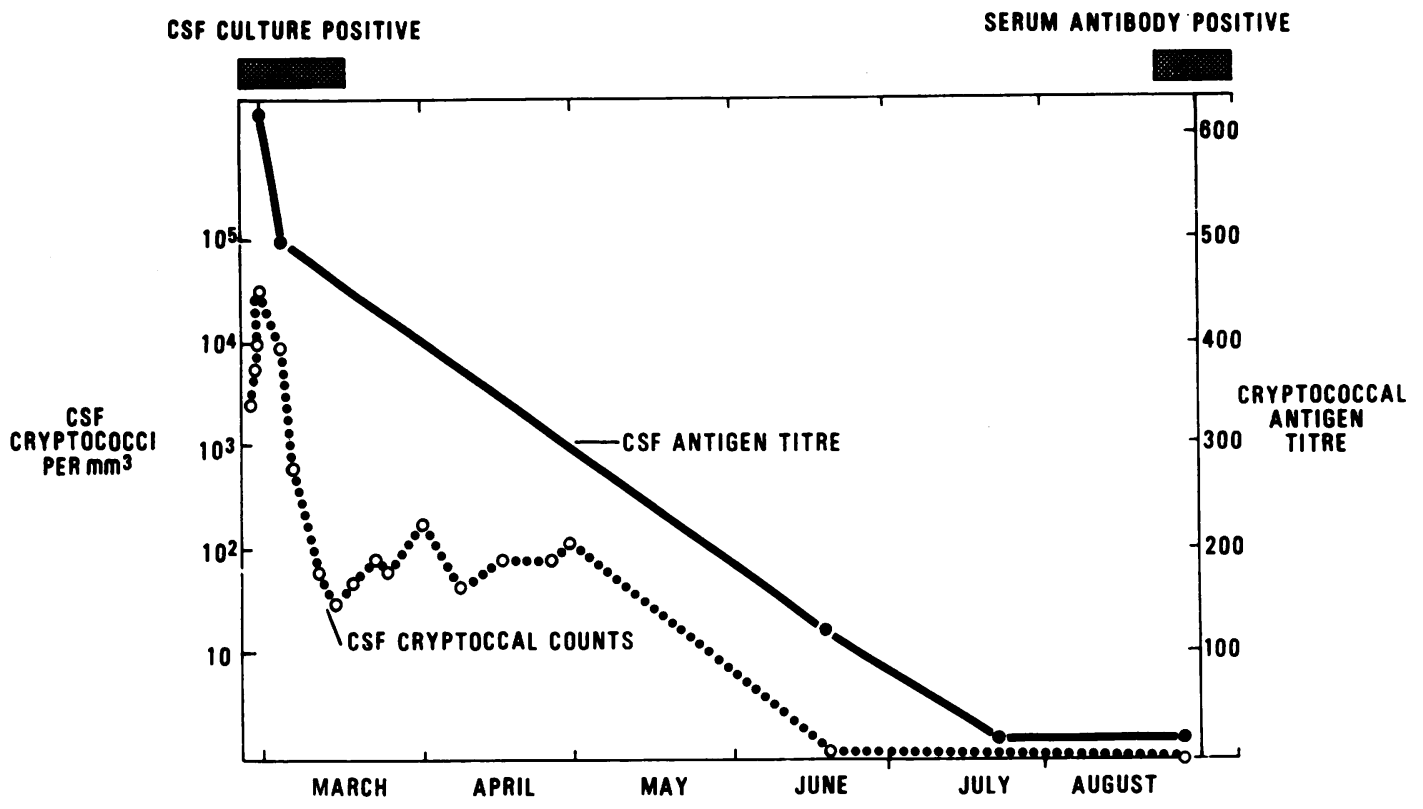

Fig. 2 Case 2. Serum and CSF results.

$1 \mathrm{~g}$ by the intrathecal route, and approximately $1.2 \mathrm{~g}$ of amphotericin intravenously. The initial regimen gave rather high serum flucytosine concentrations but satisfactory results were obtained when she had been stabilised on the lower dose (Fig. 3). CSF concentrations of flucytosine ranged from 17 to 35 $\mathrm{mg} / \mathrm{l}$. Amphotericin was undetectable in all CSF specimens examined, but in the serum a concentration of $1.5 \mathrm{mg} / \mathrm{l}$ was reached during the period of daily infusions.

Infusions of amphotericin gave rise to sweating and backache which were controlled by salicylates. Her plasma urea before treatment was $7.9 \mathrm{mmol} / 1$, and rose to $14.2 \mathrm{mmol} / \mathrm{l}$ while amphotericin was being given daily, but fell again to its original levels after amphotericin was discontinued. Her creatinine clearance was unaltered after treatment. Hypokalaemia was not a problem although one serum potassium value of $2.9 \mathrm{mmol} / 1$ was recorded. Her haemoglobin before the start of treatment was $10.9 \mathrm{~g} / \mathrm{dl}$ and fell to $7.5 \mathrm{~g} / \mathrm{dl}$, with a leuko-erythroblastic appearance of the peripheral blood film. Marrow examination revealed hypocellularity with normal cell precursors, and no evidence of infiltration. It was not possible to distinguish the effect of the antifungal agents from that of the previous chlorambucil treatment. Liver function tests were normal before treatment and did not change during treatment except for a slight transient reduction in

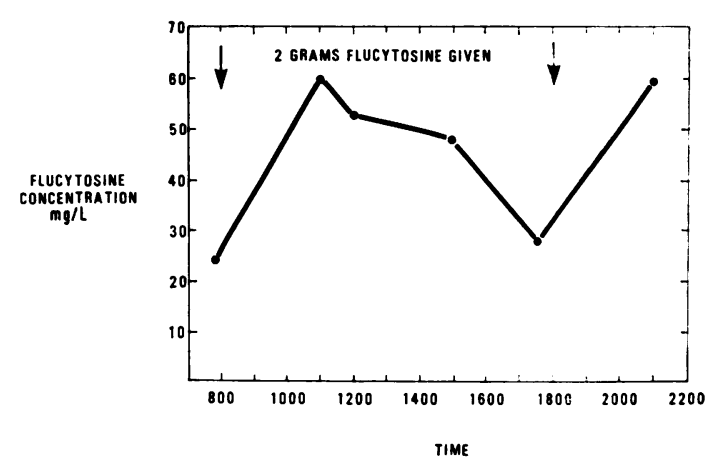

Fig. 3 Case 2. Serum flucytosine concentrations.

albumin. She suffered persistent diarrhoea, which was probably due to the flucytosine treatment.

\section{Mycological results}

CASE 1

The isolations of $C$. neoformans from CSF and the appearance of resistance to flucytosine are shown in Table 1. All isolates from case 1 had a MIC of amphotericin of approximately $0.25 \mathrm{mg} / \mathrm{l}$. No synergy, between amphotericin and flucytosine was demonstrated against flucytosine-sensitive and flucytosine-resistant isolates. 
Fig. 4 Case 1. Velvet pad replica plating of plate culture of original cryptococcal isolate on yeast morphology agar with (right) and without (left) $100 \mathrm{mg} / \mathrm{l}$ flucytosine.

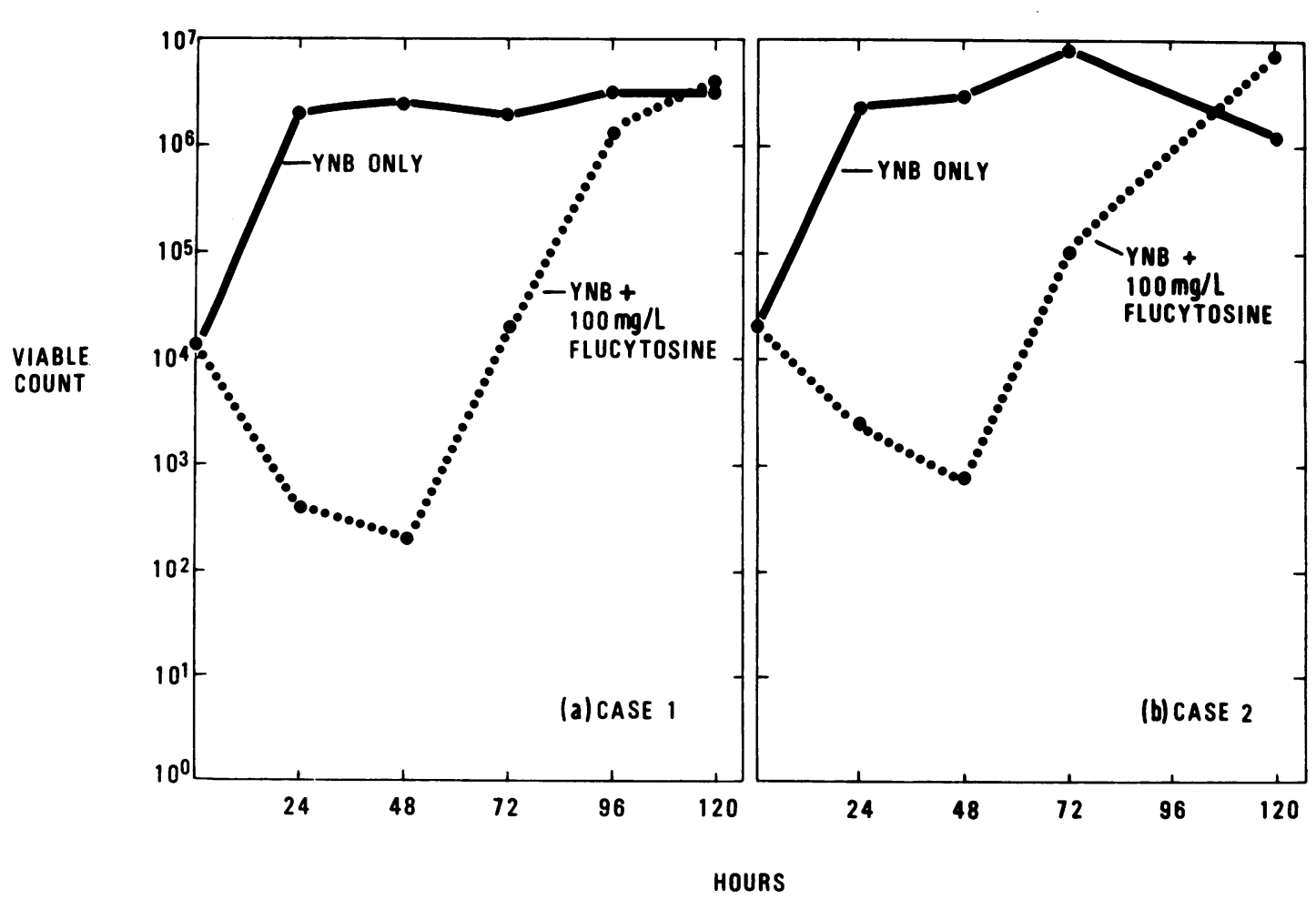

Fig. 5 Effect of incubation of cryptococcal isolates in supplemented yeast nitrogen base (YNB) with and without flucytosine: (a) original isolate from case 1 ; and (b) original isolate from case 2. 
The pre-existence of resistant mutants (MIC more than $1000 \mathrm{mg}$ flucytosine/l) among sensitive cells in the original isolate was demonstrated by the replica plating method. Figure 4 shows the result of velvet pad transfer from a plate culture of the first $C$. neoformans isolate from case 1 on to yeast morphology agar, with and without $100 \mathrm{mg} / \mathrm{l}$ flucytosine. Colonies of resistant cryptococci can be seen on the flucytosine-containing medium. Repeated subculture from the flucytosine-free plates from the exact area corresponding to the position of the mutant colonies on the flucytosine-containing plates provided a resistant culture which had not previously been exposed to flucytosine.

Growth of the original isolate in supplemented yeast nitrogen base with and without $100 \mathrm{mg} / \mathrm{l}$ flucytosine is shown in Figure 5a. The viable count was at first decreased by the presence of the flucytosine, but the resistant mutants survived and grew up to counts similar to those achieved earlier in the medium without flucytosine. Cells from the flucytosine-containing culture at five days were uniformly highly resistant to flucytosine.

\section{CASE 2}

The main laboratory findings are summarised in Figure 2. Although cryptococci continued to be visible in the CSF for four months, none was cultured after 10 days of treatment, and all isolates obtained were sensitive to flucytosine (MIC $2 \mathrm{mg} / \mathrm{l}$ ) and to amphotericin (MIC $0.25 \mathrm{mg} / \mathrm{l}$ ). No synergy between the agents was demonstrated. Cryptococcal antigen in serum and CSF fell in titre from over $1 / 600$ to $1 / 20$ after six months, and cryptococcal antibody became detectable at that time.

As in case 1, resistant mutants (MIC more than $1000 \mathrm{mg}$ flucytosine/l) could be obtained in the laboratory from the original isolate of case 2. Figure $5 \mathrm{~b}$ shows the results of growth of this isolate in supplemented yeast nitrogen base with and without 100 $\mathrm{mg} / \mathrm{l}$ flucytosine. Resistant mutants, however, were not isolated from the patient during combined therapy.

\section{Discussion}

Amphotericin B is still generally regarded as the standard chemotherapy for cryptococcal meningitis, and successful treatment has been reported in cases associated with adrenocorticosteroid-treated systemic lupus erythematosus (Collins et al., 1972; Khan and Sbar, 1975). Nevertheless, penetration of amphotericin B into many body sites, including the CSF, is poor; and the symptomatic and objective side-effects of this drug may be severe, renal impairment in particular being almost invariable with effective treatment (Bennett, 1974a). Flucytosine is better tolerated and less toxic (Cartwright, 1975) and penetrates well into most body spaces, and successful cures have been reported in the literature (Utz et al., 1969). Failures of treatment, and relapse after apparently successful treatment, are common with both drugs (Utz et al., 1975). The main problem with flucytosine is the emergence during treatment of cryptococci resistant to the drug (Block et al., 1973) as occurred in our case 1. Flucytosine-resistant mutants occur in vitro at a rate of approximately 1 in $4 \times 10^{6}$ in most fungal cultures tested (Scholer, 1976). They vary in their degree of resistance and growth rate in the presence of flucytosine but include clones indifferent to high concentrations of the drug (Normark and Schönebeck, 1972). Such mutants could be demonstrated in both the original isolates from the patients reported here and in several other clinical isolates tested by us. It is easy to see that selective growth of mutants may occur in vivo when large populations of cryptococci, not exposed to effective body defences, are treated with flucytosine. In this respect the situation may parallel the treatment of cavitary tuberculosis with a single antibiotic.

This leads to the rationale for the use of the two drugs in combination. The presence of amphotericin may prevent the multiplication of surviving flucytosine-resistant mutants; while immediate high dosage of flucytosine produces anticryptococcal activity throughout the body, without toxic effects, during the time that maximal amphotericin activity is gradually obtained, in serum, over a number of days. It may be that the lower dosage of amphotericin can be used in this situation, but we felt that in view of the patients' underlying disease we should give full dosage, although we stopped the amphotericin in case 2 earlier than we should have done if we had been using it alone. The low concentrations of amphotericin obtained in body fluids other than serum probably do not fairly represent the antifungal activity in extravascular sites where the amphotericin may be bound to cell membranes (Bennett, 1974a); but it has been suggested that amphotericin should be given by the intrathecal route while large numbers of cryptococci are present in the CSF itself (Tobias et al., 1976).

In addition, synergy between the two drugs has been demonstrated in the laboratory (Medoff et al., 1971) although we were unable to show this with the isolates from these two patients. The effectiveness of combination treatment has been shown in animal experiments (Block and Bennett, 1973) and the first encouraging results with human cryptococcosis are beginning to appear (Utz et al., 1975). Medoff and Kobayashi (1975) suggest that amphotericin's stimulating effect on host immunity may play a part 
in the effectiveness of the combination in vivo. They warn, however, that the reverse effect may be achieved in some situations, and that there is tissueculture evidence that the combination may show synergistic toxicity. The effects of flucytosine on the liver and bone marrow (Record et al., 1971) would be more likely to occur when amphotericin had caused renal impairment and accumulation of flucytosine (Bennett, 1974b). It is necessary to adjust the dose of flucytosine in cases of renal impairment (Schönebeck et al., 1973) and to assay the concentrations achieved. In our case 2, adjustment of the dosage produced satisfactory flucytosine concentrations; it was difficult to distinguish toxic effects from the background illness, but there was no definite evidence of marrow or liver impairment caused by the drug.

Both of these patients had many of the presenting features associated with failure of treatment of cryptococcosis (Diamond and Bennett, 1974)adrenocorticosteroid treatment, high CSF pressure, less than 20 leucocytes $/ \mathrm{mm}^{3}$ in the CSF, cryptococci seen in CSF film, cryptococci isolated from other sites, high cryptococcal antigen titre - and indeed both patients died. The terminal episode in case 2 is obscure and may have been the result of active cryptococcal disease. On the other hand, her progress with the combination therapy was strikingly better than that of the first patient who received flucytosine and amphotericin consecutively, in whom resistance emerged and the progress of the disease to death was almost uninterrupted. On the basis of our experience in these and other cases, and the results from other centres, we feel justified in recommending combination treatment for patients in this country with cryptococcosis intervening in severe predisposing disease, and we await with interest the results of the multicentre trial which has been set up to study this problem (Utz et al., 1975).

We thank Professor A. E. Read and Dr D. R. Coles for permission to publish these case reports, Dr Mary P. English and Dr L. W. Greenham for confirming the identity of the isolates, and the Mycological Reference Laboratory for the estimations of cryptococcal antigen and antibody.

\section{References}

Bennett, J. E. (1974a). Chemotherapy of systemic mycoses. Part 1. New Engl. J. Med., 290, 30-32.

Bennett, J. E. (1974b). Chemotherapy of systemic mycoses. Part 2. New Eng. J. Med., 290, 320-323.

Block, E. R. and Bennett, J. E. (1973). The combined effect of 5-fluorocytosine and amphotericin $B$ in the therapy of murine cryptococcosis. Proc. Soc. exp. Biol. Med. (N.Y.), 142, 476-480.
Block, E. R., Jennings, A. E., and Bennett, J. E. (1973). 5-Fluorocytosine resistance in Cryptococcus neoformans. Antimicrob. Agents Chemother., 3, 649-656.

Cartwright, R. Y. (1975). Antifungal drugs. J. antimicrob. Chemother., 1, 141-162.

Collins, J. V., Tong, D., Bucknall, R. G., and Warin, A. P. (1972). Cryptococcal meningitis as a complication of systemic lupus erythematosus treated with systemic corticosteroids. Postgrad. med. J., 48, 52-55.

Diamond, R. D. and Bennett, J. E. (1974). Prognostic factors in cryptococcal meningitis: a study in 111 cases. Ann. intern. Med., 80, 176-181.

Holt, R. J. (1975). Laboratory tests of antifungal drugs. J. clin. Path., 28, 767-774.

Kaspar, R. L. and Drutz, D. J. (1975). Rapid simple bioassay for 5-fluorocytosine in the presence of amphotericin B. Antimicrob. Agents Chemother., 7, 462-465.

Khan, M. A. and Sbar, S. (1975). Cryptococcal meningitis in steroid-treated systemic lupus erythematosus. Postgrad. med. J., 51, 660-662.

Lederberg, J. and Lederberg, E. M. (1952). Replica plating and indirect selection of bacterial mutants. $J$. 3 Bact., 63, 399-406.

Lodder, J. (ed.) (1970). The Yeasts, 2nd edition, p. 1133. North-Holland, Amsterdam and London.

Medoff, G., Comfort, M., and Kobayashi, G. S. (1971) Synergistic action of amphotericin $\mathrm{B}$ and 5-fluorocytosine against yeast-like organisms. Proc. Soc. exp. Biol. (N.Y.), 138, 571-574.

Medoff, G. and Kobayashi, G. S. (1975). Amphotericin B. Old drug, new therapy. J. Amer. med. Ass., 232, 619620.

Miles, A. A. and Misra, S. S. (1938). The estimation of the bactericidal power of the blood. J. Hyg. (Lond.), 38, 732-748.

Normark, S. and Schönebeck, J. (1972). In vitro studies of 5-fluorocytosine resistance in Candida albicans and Torulopsis glabrata. Antimicrob. Agents Chemother., 2, 114-121.

Record, C. O., Skinner, J. M., Sleight, P., and Speller, D. C. E. (1971). Candida endocarditis treated with $5-3$ fluorocytosine. Brit. med. J., 1, 262-264.

Scholer, H. J. (1976). Grundlagen und Ergebnisse der antimykotischen Chemotherapie mit 5-Fluorocytosin. Chemotherapy, 22, Supplement 1, 103-146.

Schönebeck, J., Polak, A., Fernex, M., and Scholer, H. J. $\frac{7}{0}$ (1973). Pharmacokinetic studies on the oral antimycotic agent 5-fluorocytosine in individuals with nor- $N$ mal and impaired kidney function. Chemotherapy, 18, 321-336.

Shadomy, S., Shadomy, H. J., McCay, J. A., and Utz, J. స్ P. (1969). In vitro susceptibility of Cryptococcus neoformans to amphotericin B, hamycin, and 5- 0 fluorocytosine. Antimicrob. Agents Chemother., 1968, 452-460.

Staib, F. (1962). Cryptococcus neoformans und Guizotia ${ }_{-}^{+}$ abyssinica (syn. G. oleifera D.C.) (Farbreaktion für C. $\frac{0}{0}$ neoformans). Z. Hyg. Infekt.-Kr., 148, 466-475.

Tobias, J. S. Wrigley, P. F. M., and Shaw, Elizabeth $\stackrel{\mathbb{Q}}{\stackrel{\oplus}{\oplus}}$ (1976). Combination antifungal therapy for cryptococ- $\stackrel{\mathbb{Q}}{\varrho}$ cal meningitis. Postgrad. med. J., 52, 305-308.

Utz, J. P., Garriques, I. L., Sande, M. A., Warner, J. F., 
Mandell, G. L., McGhee, R. F., Duma, R. J., and Shadomy, S. (1975). Therapy of cryptococcosis with a combination of flucytosine and amphotericin B. $J$. infect. Dis., 132, 368-373.
Utz, J. P., Tynes, B. S., Shadomy, H. J., Duma, R. J., Kannan, M. M., and Mason, K. N. (1969). 5-Fluorocytosine in human cryptococcosis. Antimicrob. Agents Chemother., 1968, 344-346.

\section{Reports and Bulletins prepared by the Association of Clinical Biochemists}

The following reports and bulletins are published by the Association of Clinical Biochemists. They may be obtained from The Publishing Department, British Medical Journal (ACB Technical Bulletins), B.M.A. House, Tavistock Square, London WC1H 9JR. Overseas readers should remit by British Postal or Money Order.

SCIENTIFIC REPORTS (price $£ 1 \cdot 00 / \$ 2.00$ each)

3 Automatic Dispensing Pipettes: an assessment of 35 commercial instruments September 1967 P. M. G. BROUGHTON, A. H. GOWENLOCK, G. M. WIDDOWSON, and K. A. AHLQUIST

4 An Evaluation of five Commercial Flame Photometers suitable for the Simultaneous Determination of Sodium and Potassium March 1970 P. M. G. BROUGHTON and J. B. DAWSON

SCIENTIFIC REVIEWS (price $£ 1 \cdot 00 / \$ 2.00$ each)

1 The Assessment of Thyroid Function March 1971 F. V. FLYNN and J. R. HOBBS

2 Renal Function Tests Suitable for Clinical Practice January 1972 F. L. MITCHELL, N. VEALL, and R. W. E. WATTS

3 Biochemical Tests for the Assessment of Fetoplacental Function May 1975 C. E. WILDE and R. E. OAKEY

TECHNICAL BULlETINS (price $£ 1.00 / \$ 2.00$ each)

9 Determination of Urea by AutoAnalyzer November 1966 RUTH M. HASLAM

11 Determination of Serum Albumin by AutoAnalyzer using Bromocresol Green October 1967 B. E. NORTHAM and G. M. WIDDOwsoN

13 An Assessment of the Technicon Type II Sampler Unit March 1968 B. C. GRAY and G. K. MCGOWAN

14 Atomic Absorption Spectroscopy: an outline of its principles and a guide to the selection of instruments May 1968 J. B. DAWSON and P. M. G. BROUGHTON

15 A Guide to Automatic Pipettes (2nd edition) June 1968 P. M. G. BROUGHTON

16 A Guide to Automation in Clinical Chemistry May 1969 P. M. G. BROUGHTON

17 Flame Photometers: a comparative list of 17 instruments readily available in Britain August 1969 P. WILDING

19 Spectrophotometers: a comparative list of low-priced instruments readily available in Britain May 1970 C. E. WILDE and P. SEWELL
20 Quantities and Units in Clinical Biochemistry June 1970 P. M. G. BROUGHTON

21 Filter Fluorimeters: A comparative list of 18 instruments September 1970 H. BRAUNSBERG and S. S. BROWN 22 Bilirubin Standards and the Determination of Bilirubin by Manual and Technicon AutoAnalyzer Methods January 1971 BARBARA BILLING, RUTH HASLAM, and N. WALD

23 Interchangeable Cells for Spectrophotometers and Fluorimeters September 1971 S. S. BROWN and A. H. GOWENLOCK

24 Simple Tests to Detect Poisons March 1972 B. W. MEADE $e t$ al.

25 Blood Gas Analysers May 1972 K. DIXON

26 Kits for Enzyme Activity Determination September 1972 S. B. ROSALKI and D. TARLOW

27 Assessment of Pumps Suitable for Incorporation into Existing Continuous Flow Analytical Systems November 1972 A. FLECK et al.

28 Routine Clinical Measurements of Transferrin in Human Serum September 1973 K. DIXON

29 Control Materials for Clinical Biochemistry (5th edition) September 1973 J. F. STEVENS

30 Notes on the Quality of Performance of Serum Cholesterol Assays September 1973 s. S. BROWN

31 Determination of Uric Acid in Blood and in Urine July 1974 R. W. E. WATTS

32 A Survey of Amino Acid Analysers Readily Available in the United Kingdom September 1974 J. E. CARLYLE and P. PURKISS

33 Definitions of some Words and Terms used in Automated Analysis November 1974 A. FLECK, R. ROBINSON, S. S. BROWN, and J. R. HOBBS

34 Measurement of Albumin in the Sera of Patients January 1975 LINDA SLATER, P. M. CARTER, and J. R. HOBBS

35 Investigation of the Validity of Temperature Correction Factors for Serum Aspartate and Alanine Transaminases March 1975 S. B. ROSALKI et al.

36 Factors Influencing the Assay of Creatinine November 1975 J. G. H. COOK 